\title{
MYXEDEMA COMA - A CAUSE FOR DELAYED RECOVERY FROM ANAESTHESIA
}

S. Shailaja, T. Gurumurthy, Kishan Shetty, K. Harshavardhan, Nita Varghese

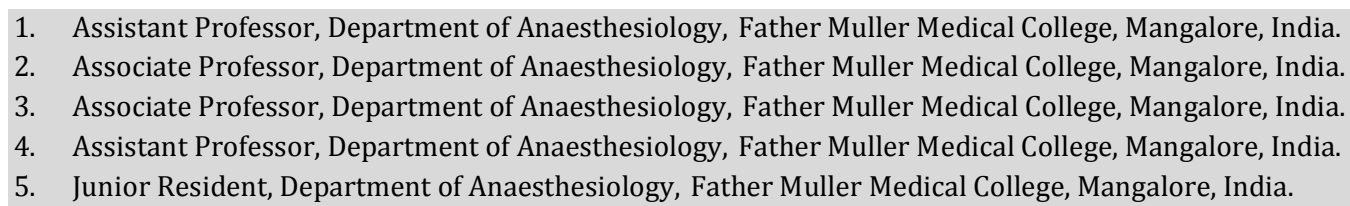

\section{CORRESPONDING AUTHOR}

Dr. Shailaja S.

Assistant Professor

Dept. of Anaesthesiology,

Father Muller Medical College,

Mangalore, 575002,Karnataka.

E-mail: drshaila@rediffmail.com

Ph: 00919845663466

ABSTRACT: Delayed recovery from anaesthesia poses a challenge to the anaesthesiologists. We report a case of 45-year-old lady, a known diabetic on oral hypoglycaemics posted for buttress plating for fracture tibia. On patient's request general anaesthesia was administered. She was haemodynamically stable throughout the procedure. At the end of the procedure, patient was apnoeic and unresponsive. She was investigated thoroughly and a diagnosis of severe hypothyroidism was made with low free $\mathrm{T}_{4}$ and $\mathrm{T}_{3}$ and high TSH levels. The patient was successfully resuscitated after treating with oral $\mathrm{T}_{4}$, gradual rewarming, and inotropic support.

KEY WORDS: Diabetes mellitus, Myxedema coma, Recovery from anaesthesia.

INTRODUCTION: Delayed recovery from anaesthesia is a major concern for anaesthesiologists, the common causes for which include residual neuromuscular blockade, central nervous system depressant drugs, hypoxemia, hypercarbia, hypotension, hypothermia, hypoglycaemia, hyperglycaemia, and electrolyte and acid-base disturbances. The incidence of unresponsiveness after general anaesthesia is $9 \% .{ }^{1}$ Anaesthesiologists frequently encounter patients with type-2 diabetes mellitus presenting for surgical procedures under general anaesthesia, and the prevalence of hypothyroidism in type- 2 diabetes mellitus is $2-17 \% \%^{2,3}$ We report a case of female with fracture tibia posted for buttress plating who had delayed recovery after general anaesthesia.

CASE REPORT: A 45-years-old female with history of fall and fracture tibia was posted for buttress plating. She was a known type- 2 diabetes mellitus patient for past three years on oral Glipizide $2.5 \mathrm{mg} /$ day. On physical examination, patient was alert and co-operative, weighed 70 kg with body mass index 31, she had a sedentary lifestyle. Except for obesity patient did not reveal any signs or symptoms of hypothyroidism. The vitals were normal. Haemogram, serum electrolytes, renal parameters and electrocardiogram were normal. Random blood sugar (RBS) was $265 \mathrm{mg} / \mathrm{dl}$, glycosylated haemoglobin was 7.8\% (Normal: 4-6.5\%). Lipid profile showed HDL $33 \mathrm{mg} / \mathrm{dl}$ (Normal: 40-60 mg/dl), LDL $154 \mathrm{mg} / \mathrm{dl}$ (Normal: <130 mg/dl), triglycerides 220 $\mathrm{mg} / \mathrm{dl}$ (Normal: $<150 \mathrm{mg} / \mathrm{dl}$ ), cholesterol $234 \mathrm{mg} / \mathrm{dl}$ (Normal: 150-200 mg/dl). 
On admission, oral glipizide was replaced with subcutaneous human insulin 12 units in the morning and 16 units in the evening. Patient was reluctant for regional anaesthesia; hence an informed consent was taken for general anaesthesia and accepted under American society of anaesthesiology physical status (ASA) II. She was premedicated with ranitidine $150 \mathrm{mg}$ oral and morphine $5 \mathrm{mg}$ intramuscular two hours prior to surgery.

This case was planned to be taken up under no sugar no insulin regimen. Morning dose of insulin was skipped. Morning RBS was $110 \mathrm{mg} / \mathrm{dl}$ and urine ketone bodies were negative. On arrival to the operating room, IV cannula was inserted and normal saline drip was started. Standard monitors were connected and anaesthesia was induced with thiopentone $300 \mathrm{mg}$ and fentanyl $50 \mu \mathrm{g}$ for intraoperative analgesia, muscle relaxation with vecuronium $5 \mathrm{mg}$ and patient was intubated. Anaesthesia was maintained with $30 \%$ oxygen in nitrous oxide. Isoflurane $0.2-0.4 \mathrm{vol} \%$ titrated to response.

Patient was haemodynamically stable throughout the procedure. She did not require any supplementation of vecuronium even though procedure lasted for $90 \mathrm{~min}$. At the end of the procedure when peripheral nerve stimulator recorded two twitches, neuromuscular blockade was reversed with neostigmine $3 \mathrm{mg}$ and glycopyrolate $0.8 \mathrm{mg}$. But, patient continued to be apnoeic and comatose, and pupils were constricted and reacting to light. Hence, naloxone $1 \mathrm{mg}$ in $100 \mathrm{ml}$ of normal saline was administered over $20 \mathrm{~min}$, patient responded with shallow breathing followed by intermittent apnoea.

Patient was shifted to post-operative ward and connected to ventilator on SIMV mode with $14 / \mathrm{min}$ respiratory rate and inspiratory: expiratory ratio of 1:2. Patient was rewarmed with forced air warming device for treatment of hypothermia. Blood was sent for investigations - sugar, electrolytes, ketone bodies and arterial blood gas analysis, all of which were normal. Blood sugars were managed by titrated insulin infusion. Meanwhile, patient developed hypotension of $80 / 50 \mathrm{mmHg}$ and was stared on dopamine infusion $12-15 \mu \mathrm{g} / \mathrm{kg} / \mathrm{min}$. Blood pressure remained the same, hence to improve myocardial contractility infusion of dobutamine $15 \mu \mathrm{g} / \mathrm{kg} / \mathrm{min}$ was added and a 12-lead ECG was taken. Blood pressure increased to 100/70 $\mathrm{mmHg}$ and ECG did not show any ischaemic changes. Blood sent for thyroid profile revealed severe primary hypothyroidism with $\mathrm{T}_{3} 0.28 \mathrm{ng} / \mathrm{ml}$ (Normal: 0.6-2.02 ng/ml), $\mathrm{T}_{4} 1.13 \mu \mathrm{g} / \mathrm{dl}$ (Normal: 5.13-14.06 $\mu \mathrm{g} / \mathrm{dl}$ ), free- $\mathrm{T}_{4} 0.112 \mathrm{ng} / \mathrm{dl}$ (Normal: 0.93-1.71 ng/dl) and TSH $172 \mu \mathrm{IU} / \mathrm{ml}$ (Normal: $0.27-5.5 \mu \mathrm{IU} / \mathrm{ml}$ ). Hence, $\mathrm{T}_{4} 200 \mu \mathrm{g}$ was administered through nasogastric tube stat dose followed by $100 \mu \mathrm{g} 8^{\text {th }}$ hourly and hydrocortisone $100 \mathrm{mg}$ IV stat dose and $8^{\text {th }}$ hourly as per endocrinologist order. Four hours later patient had good spontaneous respiratory efforts and was responding to commands, thus she was gradually weaned and disconnected from ventilator the next day. Dobutamine and dopamine were gradually tapered when blood pressure improved and stabilised. Patient was shifted to ward on second post operative day and was further managed by an endocrinologist.

DISCUSSION: Incidence of hypothyroidism is rising due to increase in proportion of patients with obesity. ${ }^{4,5}$ The rate of primary hypothyroidism in type- 2 diabetes mellitus is two times greater than non-diabetics ${ }^{6}$, hence high index of suspicion is required when there is delay in recovery from anaesthesia in diabetic patients.

Hypothyroidism is sometimes difficult to detect clinically. Patients presenting with complications of hypothyroidism are common in developing countries due to lack of cost effective screening tools. ${ }^{7}$ Myxedema coma is a rare, life threatening complication of hypothyroidism with incidence of 0.22 per million per year. ${ }^{8}$ However, mortality due to 
myxedema coma had decreased from $80 \%$ to $40 \%-20 \%$ due to increased awareness of the condition, improvement in diagnostic tools and advanced intensive care. ${ }^{9}$

Undiagnosed and severe hypothyroidism may present with myxedema coma perioperatively due to presence of multiple precipitating factors such as use of sedatives, analgesics and cold operating room temperature. Hypothyroid patients have increased sensitivity to anaesthetic agents due to alteration in drug pharmacokinetics secondary to decreased cardiac output and slow circulation time. ${ }^{10}$ They are also more prone for hypotensive episodes. ${ }^{11}$ Hypothermia lowers the threshold for encephalopathy due to failure of thermoregulatory compensatory mechanism, thus hypothyroid patients are more prone for myxedema coma in cold temperature. ${ }^{12}$

Treatment consists of administration of thyroid hormone and correction of the associated physiologic disturbances. There is a controversy that whether oral or intravenous $\mathrm{T}_{3}$ or $\mathrm{T}_{4}$ or combination of $\mathrm{T}_{3}$ and $\mathrm{T}_{4}$ should be administered during the myxedema coma. Due to non availability of intravenous form oral $\mathrm{T}_{4}$ was administered in the present case. Dutta $\mathrm{P}$ et al. ${ }^{7}$ stated that oral $\mathrm{T}_{4}$ was equally efficacious as intravenous route even in patients with gastric atony. Patients with longstanding hypothyroidism will have associated glucocorticoid deficiency thus hydrocortisone supplementation is necessary. ${ }^{13}$

The present case exhibited enhanced sensitivity to opioids, which precipitated myxedema coma as prolonged unresponsiveness following general anaesthesia (Morphine 5mg

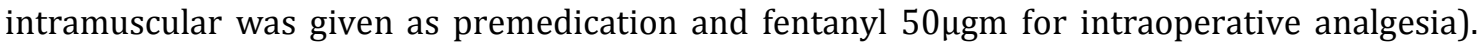
Although peak therapeutic effect of oral levothyroxine appears by 4 to 6 weeks, our patient responded to supportive measures even before normalisation of thyroid status.

Untreated severe myxedema coma may have serious problems. But, in the present case, patient did not present with any major complications due to early detection and treatment with mechanical ventilation, inotropic support, gradual rewarming and oral thyroxine supplementation.

CONCLUSION: Myxedema coma should be thought of in cases of delayed emergence from anaesthesia due to increase in proportion of hypothyroid patients and high index of suspicion is required in type- 2 diabetes mellitus patients.

\section{REFERENCES:}

1. Zelcer J, Wells DG. Anaesthesia related recovery room complications. Anaesth. Intensive care. 1987;15:168-74.

2. Perros P, McCrimmon RJ, Shaw G, Frier BM. Frequency of thyroid dysfunction in diabetic patients : value of annual screening. Diabet Med 1995;12:622-27.

3. Smith MJ. Screening for thyroid dysfunction in a community population of diabetic patients. Diabet Med 1998;15:148-50.

4. Leese GP, Flynn RV, Jung RT, Macdonald TM, Murphy MJ, Morris AD. Increasing prevalence and incidence of thyroid disease in Tayside, Scotland: the Thyroid Epidemiology Audit and Research Study. Clin Endocrinology 2008;68(2):311-16.

5. Jancovic D, Wolf P, Anderwald CH, Winhofer Y, Promintzer-Schifferl M, Hofer A, Langer F, Prager G, Ludvik B, Gessl A, Luger A, Krebs M. Prevalence of endocrine disorders in morbidly obese patients and the effects of bariatric surgery on endocrine and metabolic parameters. Obes Surg 2012 Jan;22(1):62-9. 
6. Tamez - Perez HE, Marinez E, Quintanilla - Flores DL, Tamez - Pena AL, Gutierrez Hermosillo HDiaz E. The rate of primary hypothyroidism in diabetic patients is greater than the non-diabetic population. An observational study. Med Clin (Barc) 2012 Apr 28;138(11):475-7.

7. Dutta P, Bhansali A, Masoodi S, Bhadada S, Sharma N, Rajput R. Predictors of outcome in myxedema coma : a study from a tertiary care centre. Critical Care 2008;12(1)p. $R_{1}$.

8. Galofre JC, Garcia-Mayor RV : Densidad de incidencia del coma mixedematoso. Endocrinologia 1997, 44:103-4.

9. Reinhardt W, Mann K. Incidence, clinical picture and treatment of hypothyroid coma. Results of a survey. Med Klin (Munich) 1997 Sep 15;92(9)521-4.

10. Katz J, Kadis L. Anaesthesia and Uncommon Diseases. Philadelphia, WB Saunders Company,1973, 108-14.

11. Bennett-Guerrero E, Kramer DC, Schwinn DA. Effect of chronic and acute thyroid harmone reduction on perioperative outcome. Anaesth Analg 1997;85(1):30-6.

12. Wartofsky L. Myxedema coma. Endocrinol Metab Clin N Am 2006,35:687-98.

13. Mercado DL, Petty BG. Perioperative medication management. Med Clin North Am 2003;87:41-57. 